\title{
Leucocyte proliferation in the bovine corpus luteum
}

\author{
M. Bauer, I. Reibiger and K. Spanel-Borowski \\ Department of Anatomy, University of Leipzig, Liebigstrasse 13, \\ D-04103 Leipzig, Germany
}

Leucocytes vary in type and number during the lifespan of a corpus luteum. The aim of this study was to determine whether there is an increase in the number of lymphocytes and macrophages as a result of local proliferation. Bovine corpora lutea were classified into stages of development, secretion and regression. A new double immunolabelling method was established for nuclear $\mathrm{Ki}$ 67 antigen (a marker for cell proliferation) and for leucocyte surface antigens (detection of CD2-, CD3-, CD4-, CD8-positive lymphocytes and CD14-positive monocytes). Differential cell counting was performed. Between the stages of development and regression there was an increase in the number of T-lymphocytes and macrophages.
The percentage of proliferating leucocytes in relation to the total number of proliferating cells was approximately $20 \%$ at the stage of advanced secretion and $70 \%$ at late regression. The increase in the number of proliferating leucocytes at late regression was due to CD14-positive macrophages. These macrophages migrated from small blood vessels into the septa of corpora lutea at the early stage of regression. Macrophages showed local proliferation in the late stage of regression when capillaries were no longer present. It is concluded that the physiological involution of the corpus luteum is an inflammatory-like condition, which includes local proliferation of monocytes.

\section{Introduction}

Leucocytes populate corpora lutea of several species including humans (Wang et al., 1992; Brännström and Norman, 1994; Best et al., 1996), cows (Lawler et al., 1994; Spanel-Borowski et al., 1997; Penny et al., 1999) and pigs (Standaert et al., 1991). Staining the leucocytes with the common leucocyte antibody against CD18 and counting the positive cells showed that the number of these cells increases between the stages of development, secretion and regression of the corpus luteum (SpanelBorowski et al., 1997). The leucocyte pool appears to contain subtypes that are independent of the stage of the oestrous cycle: eosinophils are found in preovulatory follicles (sheep), during the development of the corpus luteum (cows) and in the regressing corpus luteum after $\mathrm{PGF}_{2 \alpha^{-i n}-}$ duced luteolysis (Murdoch, 1987; Cavender and Murdoch, 1988). More lymphocytes (CD4- and CD8-positive) are present at the onset of functional luteolysis than in the other stages of the oestrous cycle (Penny et al., 1999). Macrophages dominate all stages of the oestrous cycle except between day 6 and day 12 (stage II, Penny et al., 1999).

Luteal leucocytes are assumed to be involved in the growth, differentiation and regression of corpora lutea by secretion of a variety of cytokines (Adashi, 1992; Brännström et al., 1994; Sunderkötter et al., 1994; Pate, 1995). These leucocytes may act in a direct or indirect

Email: baum@medizin.uni-leipzig.de manner and influence the secretion of progesterone and prostaglandin (Fairchild et al., 1991; Townson and Pate, 1994). The cellular interaction between leucocytes and luteal endothelial cells probably determines the time course and cyclic recruitment of leucocyte populations, or may induce proliferation of resident macrophages within a corpus luteum. This is deduced from a recent report on intratesticular proliferation of resident macrophages (Schlatt et al., 1999).

The major proportion of proliferating cells in the corpora lutea of rats, cows and primates are endothelial cells (Jablonka-Shariff, 1993; Zheng et al., 1994; Christenson and Stouffer, 1996). These cells represent approximately $50 \%$ of the total number of cells in a fully developed corpus luteum (Farin et al., 1986; Lei et al., 1991; Reynolds and Redmer, 1999). A substantial number of proliferating cells was observed in the regressing corpora lutea of pigs (but not in cows or sheep); however, the types of cell were not specified (Jablonka-Shariff et al., 1993; Zheng et al., 1994; Reynolds and Redmer, 1999). The regressing corpus luteum contains an abundance of macrophages as demonstrated in cows (Spanel-Borrowski et al., 1997). Under local inflammatory stimuli bone marrow-derived monocytes may divide a few times in their target tissue before they become mature macrophages (van Furth et al., 1985; van Furth, 1988); thus, immature macrophages that are proliferating may occur in the regressing bovine corpus luteum.

The aim of the present study was to determine the number of proliferating macrophages in all stages of the cyclic corpus luteum of cows. An immunohistological 
technique was established for double-labelling proliferating leucocyctes with the antibody against the nuclear Ki-67 antigen and with an antibody against leucocyte surface antigens. The Ki-67 antigen, an established marker for cell proliferation, displays all active phases of the cell cycle, that is G1, S, G2 and mitosis. The Ki-67 antigen is considered a more appropriate marker than proliferating cell nuclear antigen (PCNA), which reveals non-proliferating cells under DNA repair (Hall et al., 1993). Antibodies against different leucocyte surface antigens (CD2, CD3, CD4, CD8, CD14, CD11/18) were used to differentiate leucocyte subtypes.

\section{Materials and Methods}

Ovaries with corpora lutea were collected from nonpregnant cows within 30 min after the animals were killed at a local abattoir. Pregnancy was excluded by macroscopic examination of the uterine horns. The ovaries were kept in ice-cold 0.01 mol PBS $\left.\right|^{-1}$ until preparation at the laboratory. Each corpus luteum was dissected from cortical tissue and pieces of luteal tissue were either frozen immediately in liquid nitrogen for storage at $-80^{\circ} \mathrm{C}$ or fixed with 4\% (w/v) PBS buffered formaldehyde and embedded in paraffin wax according to the standard histological technique. The corpora lutea were classified according to the stage of the oestrous cycle stage by macroscopic appearence (Ireland et al., 1980) and histological criteria (Ricken et al., 1995; Reibiger and Spanel-Borowski, 2000). The stages of the oestrous cycle were estimated as follows: days 1-4 for early development, days 11-17 for the secretory stage, days 19-20 and subsequent days for regression. Eosinophils were present at a very early stage of development of the corpus luteum $(n=3)$, that is, $1-2$ days after ovulation. A fully developed capillary network was apparent at the secretory stage $(n=16)$ and there was a decrease in the capillary network at the stage of regression $(n=23)$. Finally, classification of the corpora lutea was confirmed by our new immunohistological data on cell proliferation (see below).

\section{Immunohistology}

Deep-frozen tissue was cut into serial sections $(10 \mu \mathrm{m})$. The sections were mounted on object slides that had been coated with poly L-lysine $(0.1 \% \mathrm{w} / \mathrm{v}, \mathrm{P}$ 8920, Sigma, Deisenhofen), air-dried for $2 \mathrm{~h}$ and stored at $-20^{\circ} \mathrm{C}$ until use. A paper glue $\left(\right.$ Cementit $^{\circledR}$ Merz and Benteli AG, Niederwangen) was used to adhere the paraffin wax sections to the slides.

The single-labelling technique for Ki-67 antigen followed the antigen retrieval procedure according to the manufacture's instructions (Dianova, Hamburg). Cryostat sections were fixed in $4 \%$ (w/v) PBS buffered formaldehyde, washed in PBS and transferred into $0.01 \mathrm{~mol}$ citrate buffer $\mathrm{I}^{-1}$ at $\mathrm{pH}$ 6.0. Buffer was bubbled up in a microwave oven and the slides were cooked at $350 \mathrm{~W}$ for $15 \mathrm{~min}$, cooled at room temperature for approximately $15 \mathrm{~min}$, washed once in aqua dest and placed in 0.05 mol Trisbuffered saline $\mathrm{I}^{-1}$ at $\mathrm{pH}$ 7.6. Subsequently, endogenous peroxidase activity was quenched with $0.3 \%(\mathrm{v} / \mathrm{v}) \mathrm{H}_{2} \mathrm{O}_{2}$ in absolute methanol for $30 \mathrm{~min}$. Non-specific protein binding sites were blocked with $1.5 \%$ (v/v) normal goat serum (Dako, Hamburg) in Tris-buffered saline for $30 \mathrm{~min}$. The slides were incubated with the primary monoclonal antibody (anti Ki-67, 1:50 in 1.5\% (v/v) goat serum, clone: Mib-5) for $1 \mathrm{~h}$ at room temperature. After the slides were washed in Tris-buffered saline, biotinylated goat antimouse antibody (1:200, Vector Laboratories, by Alexis, Grünberg) was applied as secondary antibody for $30 \mathrm{~min}$. Immunostaining was performed using the avidin-biotinperoxidase complex from the Vectostain kit (Vector Laboratories) and 3-amino-9-ethyl-carbazole (Sigma, Deisenhofen) for peroxidase detection as described by Spanel-Borowski et al. (1997).

For single labelling of endothelial cells and smooth muscle cells, paraffin wax was removed from the sections and they were rehydrated and pre-incubated with $0.05 \%$ $(\mathrm{w} / \mathrm{v})$ protease (EC 3.4.24.31, type XIV from Streptomyces griseus; Sigma-Aldrich Chemie $\mathrm{GmbH}$, Steinheim) in Trisbuffered saline for $30 \mathrm{~min}$ at room temperature. Enzyme digestion was stopped by washing extensively with Trisbuffered saline. Endogenous peroxidase activity and nonspecific immunoglobulin binding sites were blocked. Either rabbit anti-factor VIII related (FVIIIr) antigen (detection of endothelial cells, 1:1000 in normal goat serum; Dako) or mouse anti ASM-1 (detection of smooth muscle cells and pericytes, 1:250 in normal goat serum; Progen, Heidelberg) were incubated for $1.5 \mathrm{~h}$. The biotinylated secondary antibodies (goat anti-rabbit, 1:200 in normal goat serum, and goat anti-mouse, 1:200 in normal goat serum; Vector Laboratories) were applied for $30 \mathrm{~min}$ at room temperature. The final immunostaining was performed with $3^{\prime} 3^{\prime}$-diaminobenzidine $(\mathrm{DAB})$ as peroxidase substrate. Between each incubation step, sections were washed twice with Tris-buffered saline containing $0.125 \%$ (v/v) Tween 20 (Bio-Rad, Krefeld) and twice with Trisbuffered saline. Negative controls were carried out with normal goat serum instead of the primary antibody.

The protocol for the double-labelling technique used on cryostat sections was according to Lan et al. (1995) and Tornehave et al. (2000). One antigen (Ki-67) was detected with microwave oven treatment and the other antigen (leucocyte adhesion molecule) was detected separately. The Ki-67 antibody can be used in conjunction with microwave oven treatment, in contrast to the PCNA antibody which may label cell nuclei non-specifically after treatment (Heenen et al., 1998). Since the histochemical detection of peroxidase activity with the substrate DAB (Sigma-Aldrich, Deisenhofen) gave a brown heat-stable reaction product, the leucocyte surface antigen was detected first using the DAB substrate and subsequently the proliferation marker Ki-67 was visualized with the 3-amino-9ethyl-carbozole substrate, which turned red by peroxidase 
Table 1. Ratio of positively stained cells:total number of cells (\% mean \pm SEM) in bovine corpora lutea at different stages of the oestrous cycle

\begin{tabular}{|c|c|c|c|c|c|}
\hline \multirow[b]{2}{*}{ Antigen } & \multirow{2}{*}{$\begin{array}{c}\text { Early } \\
\text { development }\end{array}$} & \multicolumn{2}{|c|}{ Secretion } & \multicolumn{2}{|c|}{ Regression } \\
\hline & & Early & Advanced & Early & Advanced \\
\hline Ki-67 & $10.1 \pm 1.1$ & $\begin{array}{c}23.3 \pm 2.3 \\
(9)^{*}\end{array}$ & $\begin{array}{c}4.5 \pm 1.1 \\
(7)^{* * *}\end{array}$ & $\begin{array}{c}0.5 \pm 0.1 \\
(12)^{* * *}\end{array}$ & $\begin{array}{c}3.4 \pm 0.4 \\
(9)^{* * *}\end{array}$ \\
\hline CD18 & $47.4 \pm 13.1$ & $\begin{array}{c}4.0 \pm 0.4 \\
(7)^{*}\end{array}$ & $4.7 \underset{(5)}{ \pm} 0.7$ & $\begin{array}{c}4.9 \pm 0.3 \\
(12)\end{array}$ & $\begin{array}{c}56.4 \pm 8.9 \\
(11)^{* * *}\end{array}$ \\
\hline CD14 & $\begin{array}{c}1.7 \pm 1.0 \\
(3)\end{array}$ & $\begin{array}{c}1.6 \pm 0.2 \\
(9)\end{array}$ & $\begin{array}{c}2.2 \pm 0.3 \\
(7)^{* *}\end{array}$ & $\begin{array}{c}1.1 \pm 0.4 \\
(12)^{* *}\end{array}$ & $\begin{array}{c}36.1 \pm 9.3 \\
(11)^{* * *}\end{array}$ \\
\hline CD2 & ND & $\begin{array}{c}0.7 \pm 0.1 \\
(9)\end{array}$ & $\begin{array}{c}1.3 \pm 0.4 \\
(7)^{*}\end{array}$ & $\begin{array}{c}3.3 \pm 0.4 \\
(12)^{* *}\end{array}$ & $\begin{array}{c}7.6 \pm 0.9 \\
(11)^{* * * *}\end{array}$ \\
\hline CD8 & ND & $\begin{array}{c}0.7 \pm 0.1 \\
(7)\end{array}$ & $\begin{array}{c}1.2 \pm 0.4 \\
(5)\end{array}$ & $\begin{array}{c}2.4 \pm 0.2 \\
(10)^{* *}\end{array}$ & $\begin{array}{c}5.5 \pm 1.1 \\
(7)^{* *}\end{array}$ \\
\hline CD4 & ND & ND & $\begin{array}{c}0.2 \pm 0.1 \\
\text { (3) }\end{array}$ & $\begin{array}{c}0.5 \pm 0.1 \\
(8)\end{array}$ & $\begin{array}{c}1.2 \pm 0.2 \\
(7)^{* *}\end{array}$ \\
\hline CD3 & ND & ND & ND & $\begin{array}{c}2.6 \pm 0.5 \\
(8)\end{array}$ & $\begin{array}{c}6.8 \pm 1.4 \\
(7)^{* *}\end{array}$ \\
\hline
\end{tabular}

Number of corpora lutea in parentheses.

ND: not determined.

$* P<0.05, * * P<0.01$ and ${ }^{* * *} P<0.001$, respectively, compared with the preceding stage.

activity. All primary mouse monoclonal antibodies were diluted in $1.5 \%(\mathrm{v} / \mathrm{v})$ normal goat serum as follows: antibovine CD11/18 (anti-pan leucocytes, 1:200, clone BAQ 30A, VMRD Inc. Pullman, WA), anti-ovine CD14 (antimonocytes-macrophages, 1:80, clone VPM65, VMRD), anti-CD3 (anti-T-lymphocyte, 1:50, clone MM1A, VMRD), anti-bovine CD2 (anti-lymphocyte, 1:100, clone CC42, Serotec, Oxford) anti-bovine CD4 (anti-T-helper lymphocyte, 1:20, clone CC30, Serotec), anti-bovine CD8 (anti-Tsuppressor/cytotoxic lymphocyte, 1:20, clone CC63, Serotec). For the detection of CD11/18, CD14 and CD2 antigens, cryostat sections were fixed with formaldehyde, whereas for CD4 and CD8 antigens, sections were not fixed. The detection of CD2-positive subpopulations was performed only for regressing corpora lutea.

After blocking endogenous peroxidase activity and non-specific immunoglobulin binding sites, sections were incubated with one of the leucocyte-specific primary antibodies for at least $1.5 \mathrm{~h}$ at room temperature. Negative controls were carried out with $2 \%(\mathrm{v} / \mathrm{v})$ normal goat serum rather than the primary leucocyte-specific antibody. Additional steps were completed as described for detection of Ki-67 antigen (single labelling); however, DAB was not used as peroxidase substrate. The sections were washed, placed in Tris-buffered saline for $30 \mathrm{~min}$ and transferred into citrate buffer. Steps for the demonstration of the Ki-67 antigen were carried out using 3-amino-9ethyl-carbozole as peroxidase substrate. The sections were rinsed in distilled water and counterstained with Mayer's hemalaun and mounted in glycerine gelatine (Hollborn, Leipzig), a water soluble embedding medium.

\section{Cell counting and documentation}

Proliferating and non-proliferating leucocytes in doublelabelled sections were examined with a light photomicroscope (Axioskop, Zeiss, Jena). A $\times 40$ objective and a $1 \mathrm{~cm}^{2}$ ocular grid were used. Leucocytes were observed as dark brown cells with or without a red nucleus regardless of whether the cells were proliferating. Positive cells were counted in at least eight fields of view in a systematic random approach, and were calculated as cells per $\mathrm{mm}^{2}$. In regressing corpora lutea that contained numerous leucocytes, CD18- or CD14-positive cells were also counted, whereas leucocytes remained separate. Septa and large blood vessels were not counted. Statistically significant differences among all group means were assessed by the non-parametric Kruskal-Wallis test followed by the Mann-Whitney $U$ test.

A light photomicroscope (Axioplan 2, Zeiss) equipped with a Progress camera and a personal computer was used to take digitalized pictures. Pictures were adjusted with appropriate software (Photoeditor, Adobe Photoshop 5).

\section{Results}

\section{Proliferating cells}

The criteria used to classify the stages of the corpora lutea were confirmed by the density of $\mathrm{Ki}-67$ positive nuclei (Table 1). Dominant follicles have a large number of proliferating cells (ratio of $49.8 \pm 5.2$ and $47.5 \pm 5.0$ in the granulosa and thecal layer, respectively; Fig. 1a), 

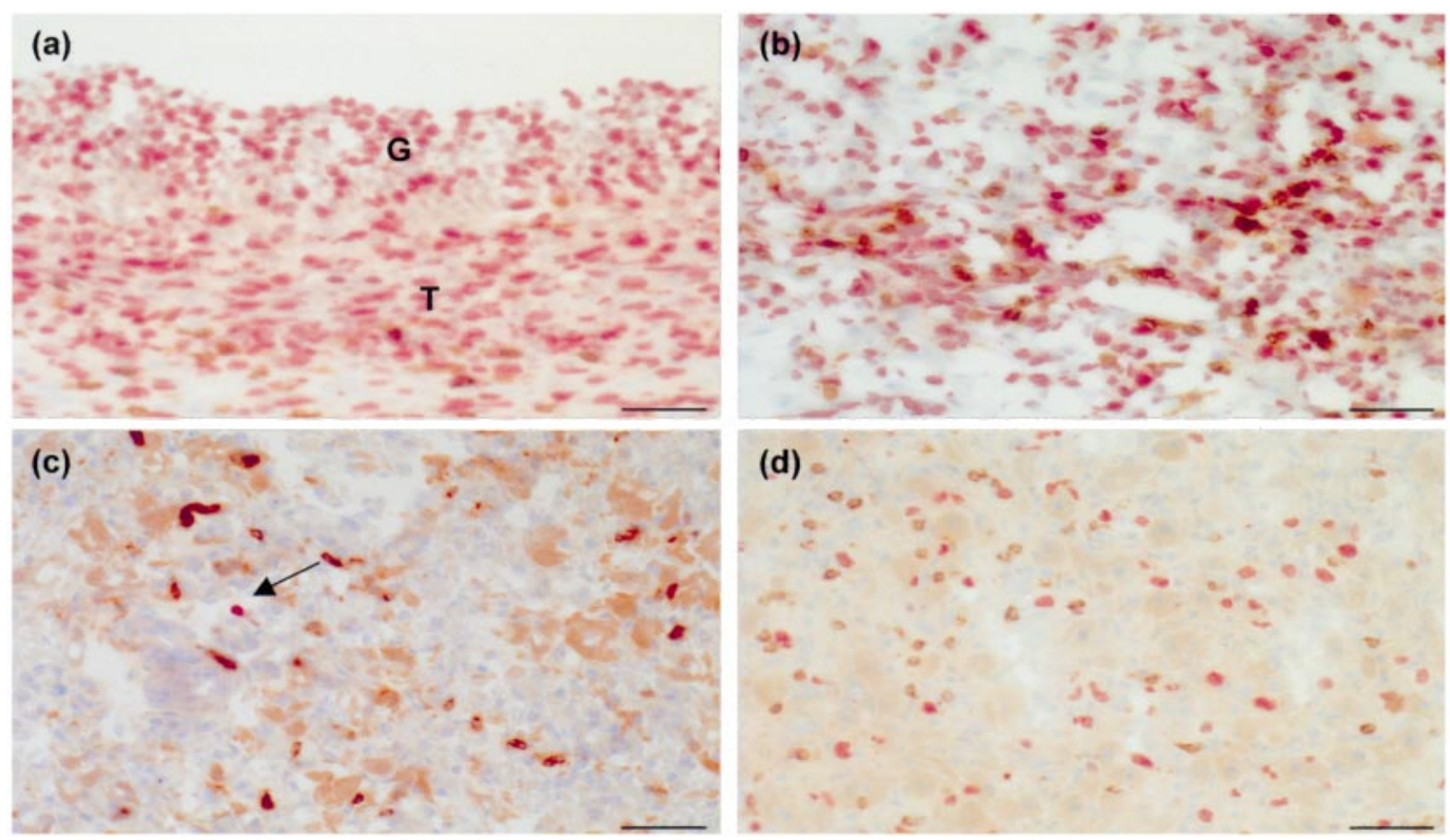

Fig. 1. Cell proliferation in a dominant bovine follicle and in bovine corpora lutea at different stages of the oestrous cycle. Double immunolabelling for the nuclear Ki-67 antigen and the leucocyte surface antigen CD18 (a-c) or CD2 (d) was carried out. (a) A dominant follicle containing numerous Ki-67-positive nuclei (red) indicating an extremely high proliferation rate in the granulosa (G) and thecal ( $\mathrm{T}$ ) layers. There are a few CD18-positive leucocytes (brown). (b) The early secretory stage is characterized by a large number of proliferating cells (red nucleus), which are either attributed to dark brown stained leucocytes or to other types of cell in the corpus luteum. (c) At the early stage of regression, there are very few proliferating cells (arrow). (d) At the late stage of regression, the number of proliferating cells (red nuclei) is greater than at the early stage of regression. Scale bars represent $25 \mu \mathrm{m}$.

whereas fewer proliferating cells were observed at the early stage of corpus luteum development. At the advanced stage of development (not shown) and at the early stage of secretion there was an increase in the number of proliferating cells (Fig. 1b). At the end of the secretory stage a low proliferation rate (ratio of $4.5 \pm 1.1$ ) was observed; however, the proliferation rate was greater than at the early stage of regression (Fig. 1c). Finally, at the advanced stage of regression, a new peak in proliferation was noted which corresponded to proliferating macrophages (Figs 1d and $2 \mathrm{~b}$ ). Corpora lutea that were at the final stages of regression were rich in arterioles, but lacked proliferating cells.

\section{Leucocyte distribution}

The different densities of Ki-67 positive cells during the oestrous cycle correlated with changes in leucocyte populations. The major CD18-positive population at the early stage of development represented eosinophils (ratio of $47.4 \pm 13.1, n=3$ ), as determined by the bilobulated nucleus in haematoxylin and eosin stained sections. After a marked decrease in the number of eosinophils, a few
CD18-positive leucocytes were detected at the stages of secretion and early regression. CD18-positive cells densely populated the corpora lutea at the late stage of regression. There was a moderate number of macrophages (CD14positive) in corpora lutea at the secretory stage, very few at the early stage of regression and a large number at the late stage of regression. There was a moderate distribution of T-lymphocytes (CD2-positive) until the advanced stage of secretion and there was a considerable increase in number between early and advanced regression. Approximately $84 \%$ of all CD2-positive cells were characterized as CD3positive T-lymphocytes. The proportion of CD8-positive T-suppressor/cytotoxic cells was 4.7 fold higher than that of CD4-positive T-helper cells.

Proliferating leucocytes were detected with the doublelabelling technique (Fig. 2, Table 2). In corpora lutea at the stages of early development and early secretion, less than $1 \%$ of all proliferating cells were CD18-positive leucocytes. At the advanced secretory and advanced regression stages of the corpus luteum, approximately $20 \%$ (ratio of $0.11 \pm 0.07$ ) and $71 \%$ (ratio of $2.39 \pm 0.44$ ) of proliferating cells were CD18-positive leucocytes, respectively.

Throughout the secretory stage there were only a 


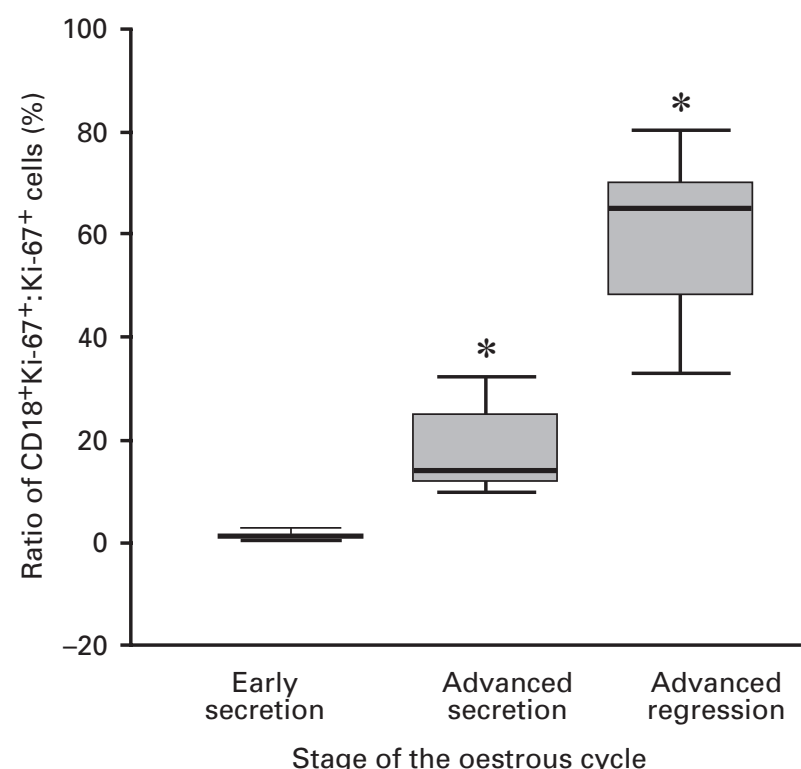

Fig. 2. Percentage of proliferating leucocytes $\left(\mathrm{CD} 18^{+}: \mathrm{Ki}-67^{+}\right.$ cells) in relation to the total number of proliferating cells (Ki-67+ cells) at the different stages of the bovine oestrous cycle. Data are shown as box plots. ${ }^{*} P<0.001$ compared with the preceding stage.

few proliferating leucocytes among the CD2- and CD14positive leucocytes $(0.8 \%$ of CD14-positive macrophages (Fig. 3a) and $1.5 \%$ of CD2-positive lymphocytes). At the advanced secretory stage of the corpus luteum, $78 \%$ of the proliferating CD2- and CD14-positive leucocytes were CD2-positive T-lymphocytes (Fig. 3c), indicating an increase of CD2-positive leucocytes over CD14-positive leucocytes. The onset of the increase in the number of leucocytes (Tab.1) at the advanced stage of regression coincided with an increase in the number of proliferating CD14positive macrophages (ratio of $1.62 \pm 0.2$, Fig. 3b). At this stage, the proliferating CD2- and CD14-positive leucocytes consisted of 95\% CD14-positive macrophages. However, unlike the macrophages, no increase in proliferating CD2-positive lymphocytes was apparent at the advanced stage of regression (Fig. 3c,d; $0.9 \%$ proliferation rate).
At the early stage of regression a large number of leucocytes infiltrated the septal areas of corpora lutea, whereas fewer leucocytes appeared among the luteal cells and capillaries (Fig. 4a,b). The disruption of the capillary bed had been initiated (Fig. 4c) as indicated by the decrease in the density of the capillaries and the appearance of arterioles (Fig. 4d). At the advanced stage of regression when the corpus luteum was crowded with leucocytes, no leucocyte infiltration via blood vessels in the septa was detected (Fig. $4 \mathrm{e}, \mathrm{f}$ ), the capillary bed was no longer visible (Fig. $4 \mathrm{~g}$ ) and many arterioles were present (Fig. 4h). Macrophages were not present in the arteriole walls.

Comparable with regressing corpora lutea, follicles undergoing atresia were invaded by CD18-positive leucocytes (Fig. 5a). Proliferation was observed in the area of the former granulosa and thecal layers and more activity was observed in the centre than at the periphery. Some of the proliferating cells were leucocytes (Fig. 5b). Proliferating leucocytes were not observed in a hyalinized atretic follicle (not shown).

\section{Discussion}

The double-immunolabelling technique used in the present study has several advantages. Firstly, the technique is easy to carry out because the secondary biotinylated antibodies, the amplification of the antibodies using avidin-biotin-peroxidase complex and the histochemical peroxidase reaction (apart from the reaction substrate) are similar for the detection of the first (leucocyte adhesion antigen) and the second (Ki-67-nuclear) antigen. Secondly the cell surface membrane and the nucleus represent different cellular compartments, thus interference in staining for the first or second antigen is avoided. Furthermore, the two antigens are located distinctly with two specific monoclonal antibodies that both originated in mice. This aspect means that unwanted binding, such as the primary antibody of the second detection step with residual free binding sites of the secondary antibody from the first step (Negoescu et al., 1994), is negligible. Finally, the DAB substrate reaction by peroxidase activity renders a water non-soluble and heat-stable brown product that represents the detection complex of the first antibody, which includes the biotin-labelled secondary antibody and the HRP-

Table 2. Ratio of positive Ki-67 stained cells:total number of cells (\% mean \pm SEM) in bovine corpora lutea at different stages of the oestrous cycle

\begin{tabular}{|c|c|c|c|c|}
\hline \multirow[b]{2}{*}{ Antigen } & \multicolumn{2}{|c|}{ Secretion } & \multicolumn{2}{|c|}{ Regression } \\
\hline & Early & Advanced & Early & Advanced \\
\hline CD18 & $0.09 \pm 0.02(9)$ & $0.17 \pm 0.03(6)$ & $0.11 \pm 0.07(12)$ & $2.39 \pm 0.44(9) *$ \\
\hline CD14 & $0.02 \pm 0.01(9)$ & $0.05 \pm 0.01(7)$ & $0.02 \pm 0.00(10)$ & $1.62 \pm 0.20(9)^{*}$ \\
\hline CD2 & $0.01 \pm 0.00(8)$ & $0.06 \pm 0.02(6)$ & $0.07 \pm 0.02(11)$ & $0.07 \pm 0.01(10)$ \\
\hline
\end{tabular}

Number of corpora lutea in parentheses.

${ }^{*} P<0.001$ compared with the preceding stage. 

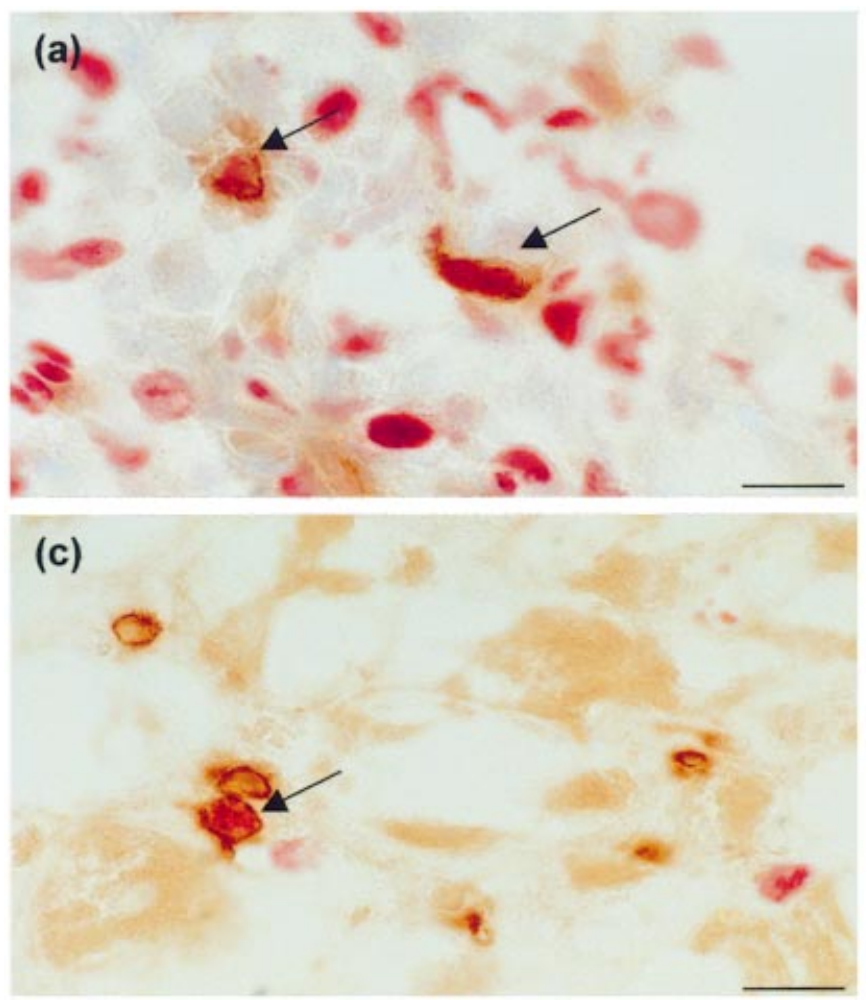

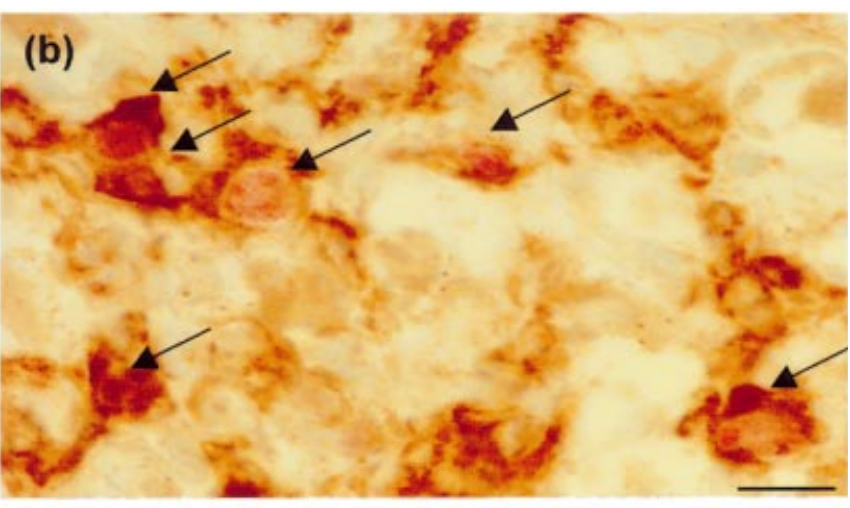

(d)

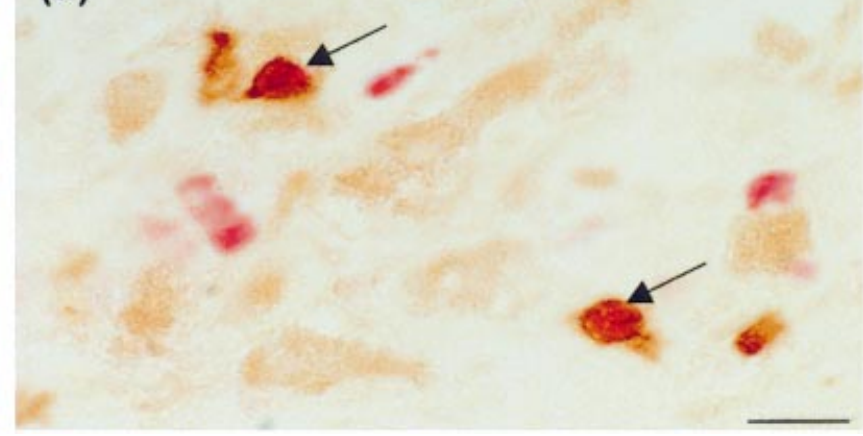

Fig. 3. Proliferating leucocytes in the bovine corpus luteum as revealed by double-immunolabelling. The antibody against the nuclear Ki-67 reveals the red nuclei of proliferating leucocytes, which are simultaneously detected by the brown staining response of leucocyte surface molecules. (a) Proliferating macrophages (arrows) at the early stage of secretion and (b) at the advanced stage of regression. Proliferating CD2- (c) and CD8-positive (d) lymphocytes (arrows). Scale bars represent $10 \mu \mathrm{m}$.

labelled avidin-biotin complex (shielding effect by Sternberger and Joseph, 1979). The DAB product enables the microwave retrieval procedure to be used for the second antigen (Ki-67 nuclear antigen), which is subsequently verified by the substrate reaction.

Three peaks of cell proliferation are apparent throughout the oestrous cycle of the bovine ovary: (i) in the dominant follicle; (ii) in the corpus luteum at the stages of advanced development and early secretion, and (iii) at the advanced stage of regression. Each peak appears to support the development of a particular type of cell, that is, granulosal and thecal cells, endothelial cells and smooth muscle cells and, finally, macrophages. The large number of proliferating endocrine cells in dominant follicles has been described by Hirshfeld, (1991). Proliferating endothelial cells in the course of angiogenesis have been recorded for the corpus luteum at the stages of development and early secretion (Jablonka-Shariff, 1993; Zheng et al., 1994; Christenson and Stouffer, 1996) and these findings were confirmed with the double-labelling technique for FVIIIr antigen and the Ki-67 antigen. Proliferating macrophages have not been observed in the corpus luteum at the advanced stage of regression. The small number of proliferating cells observed at the early stages of development of corpora lutea, probably represents a resumption in cell proliferation, which is reduced to zero in the preovulatory follicle (Spanel-Borowski et al., 1981).

In the present study between the stages of development and regression T-lymphocytes increased in number, and suppressor/cytotoxic (CD8-positive) lymphocytes were dominant, as also observed by Penny et al. (1999). As a result of a decrease in endothelial cell proliferation in the advanced secretory stage, there is a relative increase in proliferating T-lymphocytes (78\%) in relation to the pool of proliferating cells. However, in relation to the total number of lymphocytes, only about 3\% of proliferating CD2-positive lymphocytes were observed throughout the oestrous cycle. This value may represent a basic influx of lymphoblasts from the blood.

Regressing corpora lutea are densely populated by macrophages, which phagocytose luteal cell debris (Paavola, 1979). The luteal macrophages are attracted by the MCP-1 protein, a chemokine used for the recruitment of macrophages, which is upregulated in regressing corpora lutea (Townson et al., 1996; Bowen et al., 1999). In the present study it was established that at the early stage of regression, CD18-positive leucocytes preferentially populate the septa of corpora lutea, whereas at the advanced stage of regression, numerous leucocytes were observed among thick-walled arterioles. The leucocytes were identified as 

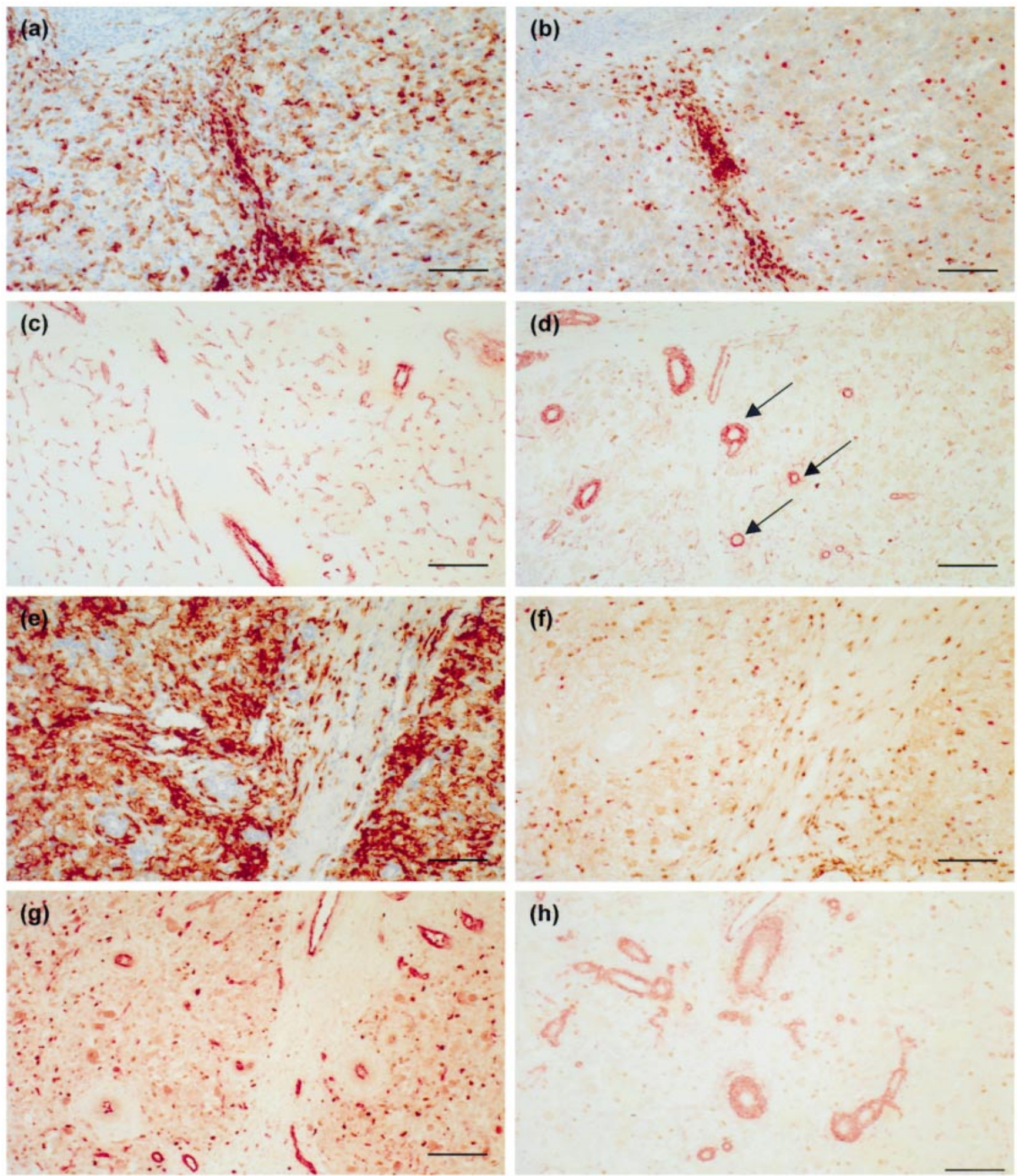

Fig. 4. Leucocyte distribution in the regressing bovine corpus luteum. Single labelling for CD18 (a,e) and CD2 (b,f) on leucocytes, for FVIIIr antigen on endothelial cells (c,g) and for ASM-1 on smooth muscle cells (d,h). CD18-positive leucocytes (a) and CD2-positive lymphocytes (b) are preferentially found in the septa at the early stage of regression (a-d). At this stage, capillaries begin to disappear (c), and arterioles (arrows) are developing (d). At the advanced stage of regression (e-h) when the luteal tissue is crowded with CD18positive leucocytes, septa contain a few CD18- (e) and CD2-positive leucocytes (f). CD2- and CD18-positive cells are not observed in the vessel wall. At this stage the capillary is no longer visible (g) and numerous thick-walled arterioles have developed (h). Scale bars represent $50 \mu \mathrm{m}$. 

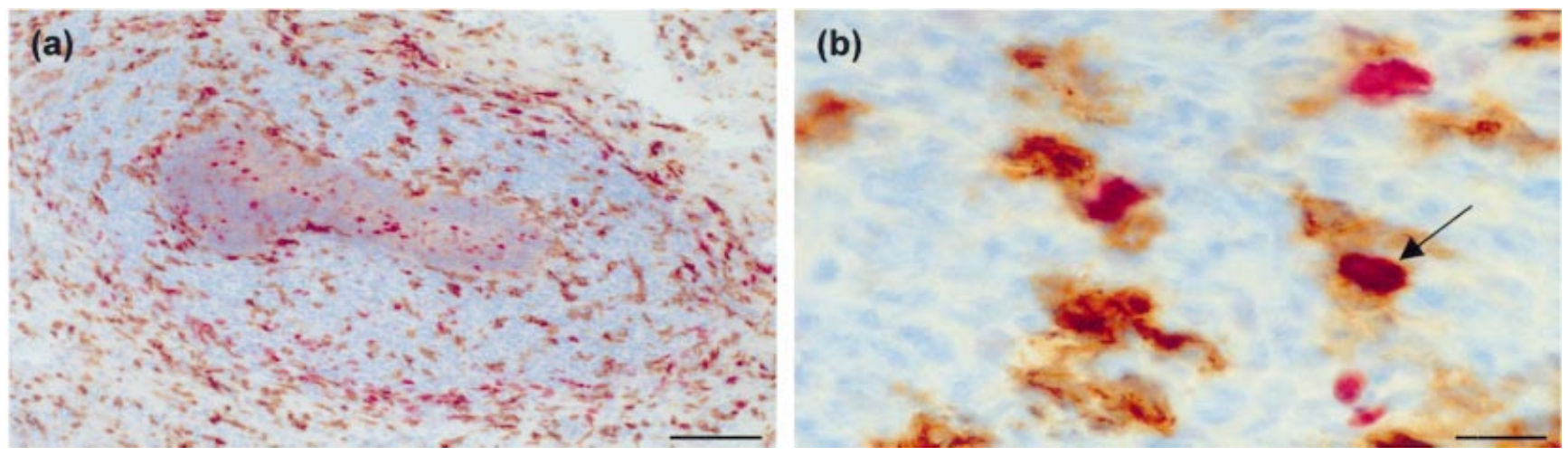

Fig. 5. A regressing bovine antral follicle heavily infiltrated by CD18-positive cells. (a) Proliferating cells (red) are apparent in the former granulosa and thecal layers. (b) A proliferating macrophage (arrow) is noted in the thecal layer. Double-immunolabelling for the Ki-67 antigen and the CD18 antigen (a) or the CD14 antigen (b). Scale bars represent (a) $50 \mu \mathrm{m}$ and (b) $10 \mu \mathrm{m}$.

macrophages, and in consideration of the macrophagedependent proliferation at the advanced stage of regression, the macrophages in regressing corpora lutea appear to have two sources of origin: (i) the septal blood vessels through which monocytes migrated from the blood into corpora lutea at the early stage of regression; and (ii) the emigrating monocytes which proliferate under suitable haematopoietic surroundings, such as the local production of macrophage colony stimulating factor.

Under normal steady-state conditions approximately $5 \%$ of monocytes divide once or twice after they arrive at their target organ (van Furth, 1988). Therefore it is assumed that more than $90 \%$ of tissue macrophages are renewed by an influx of monocytes. Under acute inflammation, a local increase in the number of macrophages is due to an influx of monocytes and to their local proliferation from day 2 onwards (van Furth, 1988). The kinetics of macrophages reported under pathological conditions appear to play a role in the physiological involution of the corpus luteum, which may be considered as an inflammatory-like condition and should not be compared with the proliferation of resident macrophages in the developing rat testis (Schlatt et al., 1999).

In summary, a new double-immunolabelling technique for microwave-sensitive and non-sensitive antigen was used to demonstrate a steady-state number of proliferating leucocytes in bovine corpora lutea throughout the oestrous cycle. In contrast, an increase in proliferating macrophages occurs in regressing corpora lutea. This increase is initially due to an influx of monocytes (early regression), and subsequently by local proliferation (advanced regression). The local proliferation of macrophages appears to compensate for post-capillary venules which, when present, are responsible for leucocyte recruitment.

This study was financially supported by the Centre of Clinical Research (IZKF, project B6) at the University of Leipzig.

\section{References}

Adashi EY (1992) The potential relevance of cytokines to ovarian physiology Journal of Steroid Biochemistry and Molecular Biology 5 439-444

Best CL, Pudney J, Welch WR, Burger N and Hill JA (1996) Localization and characterization of white blood cell populations within the human ovary throughout the menstrual cycle and menopause Human Reproduction 11 790-797

Bowen JM, Towns R, Warren JS and Landis Keyes P (1999) Luteal regression in the normally cycling rat: apoptosis, monocyte-chemoattractant protein-1 and inflammatory cell involvement Biology of Reproduction $60740-746$

Brännström M and Norman RJ (1994) Involvement of leucocytes and cytokines in the ovulatory process and corpus luteum function Human Reproduction 8 1762-1775

Brännström M, Pascoe V, Norman RJ and McClure A (1994) Localizaton of leucocyte subsets in the follicle wall and in the corpus luteum throughout the human menstrual cycle Fertility and Sterility $\mathbf{6 1}$ 488-495

Cavender JL and Murdoch WJ (1988) Morphological studies of the microcirculatory system of periovulatory ovine follicles Biology of Reproduction 39 989-997

Christenson LK and Stouffer RL (1996) Proliferation of microvascular endothelial cells in the primate corpus luteum during the menstrual cycle and simulated early pregnancy Endocrinology 137 367-374

Fairchild DL and Pate JL (1991) Modulation of bovine luteal cell synthetic capacity by interferon-gamma Biology of Reproduction 44 357-363

Farin CE, Moeller CL, Sawyer HR, Gamboni F and Niswender GD (1986) Morphometric analysis of cell types in the ovine corpus luteum throughout the estrous cycle Biology of Reproduction 35 1299-1308

Hall PA, McKee PH, Menage HD, Dover R and Lane DP (1993) High levels of p53 protein in UV-irradiated normal human skin Oncogene $\mathbf{8}$ 203-207

Heenen M, Thiriar S, Noel JC and Galand P (1998) Ki-67 immunostaining of normal human epidermis: comparison with $3 \mathrm{H}$-thymidine labelling and PCNA immunostaining Dermatology 197 123-126

Hirshfield AN (1991) Development of follicles in the mammalian ovary International Review of Cytology 124 43-101

Ireland JJ, Murphee RL and Coulson PB (1980) Accuracy of predicting stages of bovine estrous cycle by gross appearence of the corpus luteum Journal of Dairy Science 63 155-160

Jablonka-Shariff A, Grazul-Bilska AT, Redmer DA and Reynolds LP (1993) Growth and cellular proliferation of ovine corpora lutea throughout the ovine estrous cycle Endocrinology 133 1871-1879 
Lan HY, Mu W, Nikolic-Paterson DJ and Atkins RC (1995) A novel, simple, reliable and sensitive method for multiple immunoenzyme staining: use of microwave oven heating to block antibody crossreactivity and retrieve antigens Journal of Histochemistry and Cytochemistry 43 97-102

Lawler DF, Hopkins J and Watson ED (1999) Immune cell populations in the equine corpus luteum throughout the oestrous cycle and early pregnancy: an immunohistochemical and flow cytometric study Journal of Reproduction and Fertility 117 281-290

Lei ZM, Chegini A and Rao ChV (1991) Quantitative cell composition of human and bovine corpora lutea from various reproductive states Biology of Reproduction 44 1148-1156

Murdoch WJ (1987) Treatment of sheep with prostaglandin F2 alpha enhances production of a luteal chemoattractant for eosinophils American Journal of Reproductive Immunology and Microbiology 15 $52-56$

Negoescu A, Labat-Moleur F, Lorimier P, Lamarcq L, Guillermet C, Chambaz E and Brambilla E (1994) F(ab) secondary antibodies: a general method for double immunolabeling with primary antisera from the same species. Efficiency control by chemiluminescence Journal of Histochemistry and Cytochemistry 42 433-437

Paavola LG (1979) The corpus luteum of the guinea pig. Fine structure of macrophages during pregnancy and postpartum luteolysis and phagocytosis of luteal cells American Journal of Anatomy 154 337-364

Penny LA, Armstrong D, Bramley TA, Webb R, Collins RA and Watson ED (1999) Immune cells and cytokine production in the bovine corpus luteum throughout the oestrous cycle and after induced luteolysis Journal of Reproduction and Fertility 115 87-96

Pate JL (1995) Involvement of immune cells in regulation of ovarian function Journal of Reproduction and Fertility 49 365-377

Reibiger I and Spanel-Borowski K (2000) Difference in localization of eosinophils and mast cells in the bovine ovary Journal of Reproduction and Fertility 118 243-249

Reynolds LP and Redmer DA (1999) Growth and development of the corpus luteum Journal of Reproduction and Fertility Supplement $\mathbf{5 4}$ 179-189

Ricken AM, Spanel-Borowski K, Saxer M and Huber PR (1995) Cytokeratine expression in bovine corpora lutea Histochemistry 103 345-354

Schlatt S, de Kretser DM and Hedger MP (1999) Mitosis or resident macrophages in the adult rat testis Journal of Reproduction and Fertility 116 223-228

Spanel-Borowski K, Trepel F, Schick P and Pilgrim C (1981) Aspects of cellular proliferation during follicular atresia in the dog ovary Cell and Tissue Research 219 173-183

Spanel-Borowski K, Rahner P and Ricken AM (1997) Immunolocalization of CD18-positive cells in the bovine ovary Journal of Reproduction and Fertility 111 197-205

Standaert FE, Zamora CS and Chew BP (1991) Quantitative and qualitative changes in blood leucocytes in the porcine ovary American Journal of Reproductive Immunology 25 163-168

Sternberger LA and Joseph SA (1979) The unlabeled antibody method. Contrasting color staining of paired pituitary hormones without antibody removal Journal of Histochemistry and Cytochemistry 27 1424-1429

Sunderkötter C, Steinbrink K, Goebeler M, Bhardwaj R and Sorg C (1994) Macrophages and angiogenesis Journal of Leucocyte Biology $\mathbf{5 5}$ $410-422$

Tornehave D, Hougaard DM and Larsson LI (2000) Microwaving for double indirect immunofluorescence with primary antibodies from the same species and for staining of mouse tissues with mouse monoclonal antibodies Histochemistry and Cell Biology 113 19-23

Townson DH and Pate JL (1994) Regulation of prostaglandin synthesis by interleukin-1 beta in cultured bovine luteal cells Biology of Reproduction $\mathbf{5 1}$ 480-485

Townson DH, Warren JS, Flory CM, Naftalin DM and Keyes PL (1996) Expression of monocyte chemoattractant protein-1 in the corpus luteum of the rat Biology of Reproduction 54 513-520

Van Furth R (1988) Phagocytic cells: development and distribution of mononuclear phagocytes in normal steady state and inflammation. In Inflammation. Basic Principles and Clinical Correlates pp 281-295 Eds JI Gallin, IM Goldstein and R Snyderman. Raven Press, New York

Van Furth R, Nibbering PH, Van Dissel JT and Diesselhoffden Duld MMC (1985) The characterization, origin and kinetics of skin macrophages during inflammation Journal of Investigation of Dermatology $\mathbf{8 5}$ 398-402

Wang LJ, Pascoe V, Petrucco OM and Norman RJ (1992) Distribution of leucocyte subpopulations in the human corpus luteum Human Reproduction 7 197-202

Zheng J, Fricke PM, Reynolds LP and Redmer DA (1994) Evaluation of growth, cell proliferation and cell death in bovine corpora lutea throughout the estrous cycle Biology of Reproduction 51 623-632

Received 12 May 2000.

Accepted 25 August 2000. 